\title{
Introduction: Civilians, Lunacy and the First World War
}

Britain declared war against Germany on 4 August 1914. For the next four years military priorities overrode those of civilians. The entire population faced hardships, but for those people designated "pauper lunatics" in public asylums, life became very harsh. At the beginning of the war, the asylums were a story of good intentions gone awry, the failed dreams of social reformers and psychiatrists. They had become "vast warehouses

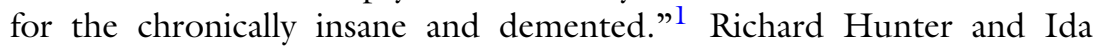
Macalpine, in their history of Colney Hatch Asylum, commented about the gloomy picture: "Custodial care was forced on asylums as a way of life....paralysed by sheer weight of numbers of patients" and financial constraints. "Nothing", they said, showed "more blatantly how relentless pressure for more and more beds forced the asylum further and further away from the idea of a hospital." 3

Public lunatic asylums in England and Wales changed in the decades before the war, arguably for the worse. Reflecting Hunter and Macalpine's dismay, earlier good intentions such as implementing "moral treatment", a social intervention involving trust, sympathy and group activities, alongside good food, fresh air, occupation and exercise, disappeared, even though the approach benefitted patients with reversible disorders of recent onset and those chronically unwell on long-stay wards. ${ }^{4}$ Alongside moral treatment, principles of "non-restraint" were valued, but not uniformly implemented. Both these methods were effective and gained

(C) The Author(s) 2021

C. Hilton, Civilian Lunatic Asylums During the First World War, Mental Health in Historical Perspective, https://doi.org/10.1007/978-3-030-54871-1_1 
prominence in smaller institutions through the work of enthusiastic lay leaders, such as the Tuke family at the Retreat in York, and medical leaders such as John Conolly at Hanwell and Robert Gardiner Hill at Lincoln. The methods worked less well in larger asylums, and never achieved widespread implementation, remaining as an ideal rather than reality.

Many other aspects of the asylum changed, influenced by stakeholders with different opinions, including doctors, lawyers, social reformers and the general public. Sometimes they agreed on priorities, but often not. The role of the medical profession became more dominant, in part due to legislation which stipulated that every institution of more than 100 lunatics must have a resident physician. ${ }^{5}$ No other profession vied for the leadership. ${ }^{6}$ New lunacy laws became more rigid and complex, tending to focus on the safety of the public rather than on the wellbeing of those suffering from mental disorders.

By 1870, public asylums had an average of 500 beds. Total annual admissions rose steeply after 1890, associated with the new Lunacy Act, but then stayed roughly in line with demographic trends (Fig. 1.1). ${ }^{7}$ The death rate remained stable, but the discharge rate declined. ${ }^{8}$ There is no evidence that the type or severity of mental disorders accounted for the changes. The increasing size of asylums, beyond that which could be accounted for by demographic changes, is likely to have been due to the decades-long mental disability caused by chronic psychotic disorders, such as schizophrenia, ${ }^{9}$ accompanied by a changing balance of therapeutic interventions and custodial care. By the beginning of the war, in England and Wales, an average asylum had 1000 beds $^{10}$ and over 100,000 people were certified as pauper lunatics. Wartime shortages of staff and material goods, and overcrowding after the War Office requisitioned asylums to use as military hospitals, were associated with a calamitous fall in standards of care for mentally unwell civilian patients. The situation was a sad commentary on the low social priorities attached to people identified as suffering from mental disorders. ${ }^{11}$

A substantial historiography exists on "shell shock", the syndrome of mental disturbances suffered by war-traumatised soldiers during the First World War. ${ }^{12}$ By contrast, the historiography of civilian asylums and their patients at the same time is meagre, featuring in a few academic journal articles and chapters in some general asylum histories. ${ }^{13}$ No in-depth historical studies have specifically drawn together the various elements of the story to provide a contextualised and detailed analysis, as this book sets out to do. It tells the story of four asylums on the periphery of 


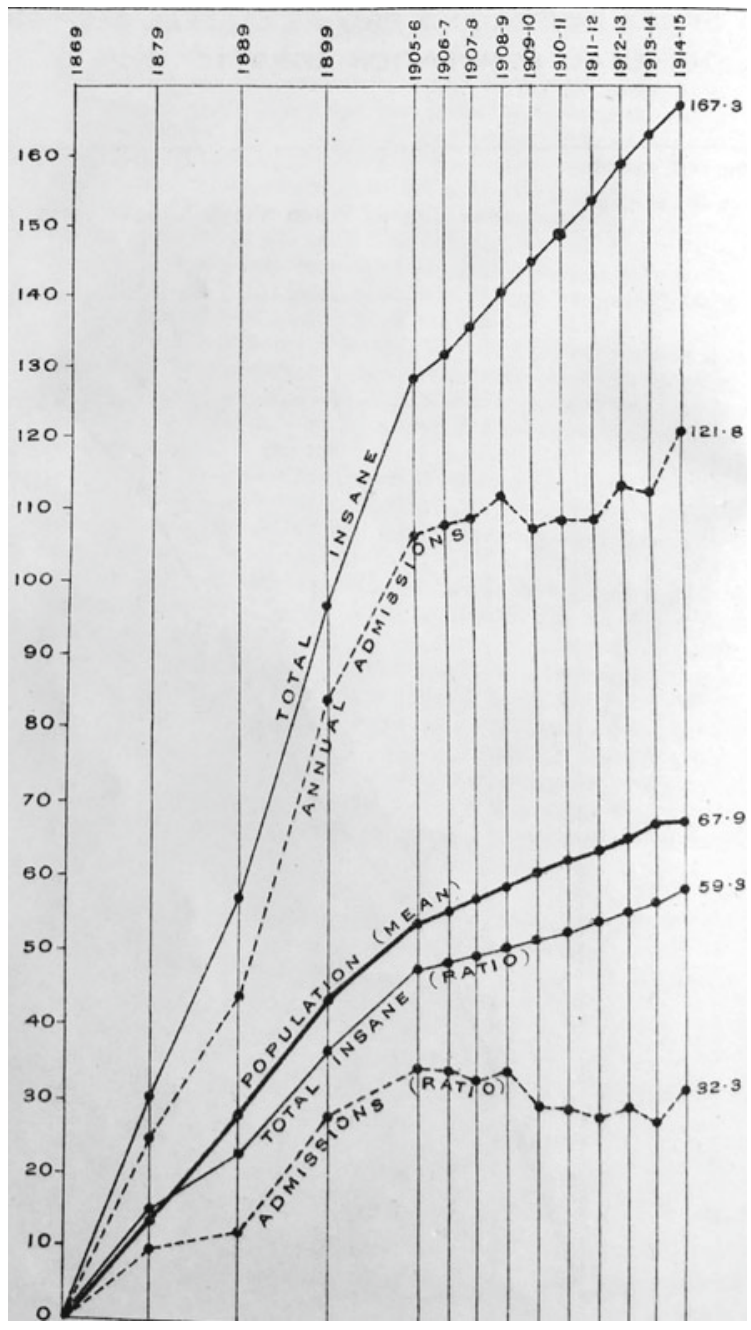

Fig. 1.1 Percentage change in "insane" patients relative to population of England and Wales (1869-1915). From top to bottom: Patients resident ("total insane"); Annual admissions; Population of England and Wales; Ratio of patients to population; Ratio of admissions to population. (First Annual Report of the Board of Control, for the Year 1914 (London: HMSO, 1916), between pp. 8-9). 
London to the north of the River Thames at a time of national turmoil, when intense austerity, deprivation and competing priorities affected those within them. The narrative overlaps with the direct effects of war on the mental health of military personnel and civilians living in the community, material which is used here to help contextualise and explain what happened in the asylums. The asylum story may also contribute to debate and shed light on the mechanisms and processes underlying standards of mental health services in other periods of austerity, including in the first decades of the twenty-first century.

This study covers the period from just before the conflagration through to the beginnings of post-war reconstruction. It tries to put the raison d'etre of the asylum - the patients and their mental health-in the foreground, with the people caring directly for them close behind. It explores the decision making and actions of those in authority over the asylums and the work of staff looking after the patients. It focusses on how the public asylum system provided care and treatment, how standards were envisaged and whether or not they were achieved. It brings together knowledge, ideas and attitudes about mental illness at the time, including political, scientific, medical, economic and popular cultural aspects.

\section{Historiography of the Asylums}

To comprehend how the asylums coped with the crisis of the Great War, it is necessary to understand their development, and disentangle fact from fiction. Mid- to late twentieth century historical interpretation of the lunatic asylums was contentious and damning, including the persuasive and influential analyses by Andrew Scull and Michel Foucault. Scull took as his starting point that the asylums, mainly established in the nineteenth century, were associated with defining a problem population and incarcerating them "in a specialised, bureaucratically organised, state-supported asylum system which isolated them geographically and symbolically from the larger society." 14 Foucault also attributed asylums' rural locations to the public desire to segregate "mad" people from the majority of the population, drawing analogies between asylums and leper houses of the middle ages. ${ }^{15}$ Even though, like leprosy, mental disorders were tainted by fear and stigma, in the nineteenth century there was also a public perception that people with disturbed minds required protection, care and compassion. These notions contributed constructively to new lunacy legislation, asylum building and asylum care in England. ${ }^{16}$ Despite 
good intentions of the reformers, as sometimes revealed verbatim in their reports in Hansard, ${ }^{17}$ Scull and Foucault identified the underlying ethos of the asylums as inherently and inevitably damaging to those within. Their conclusions linked to the theoretical and ideological standpoints which they held. Scull took a Marxist perspective in his analysis, ${ }^{18}$ which fits with his description of asylums as "Warehouses of the Unwanted", "largely receptacles for the confinement of the impossible, the inconvenient and the inept", 19 the economically unproductive sector of the population. Foucault's analysis was cotemporaneous and convergent with that of the anti-psychiatry movement, which regarded mental illness as socially fabricated and those afflicted as wrongfully confined and medicated. Anti-psychiatry activists who wrote at the same time as Foucault included RD Laing and Thomas Szasz who expounded on social causes of insanity, and Erving Goffman, who scrutinized regimes of institutional living, with particular attention to their harmful effects. ${ }^{20}$ David Cooper, the psychiatrist said to have coined the term "anti-psychiatry", wrote the introduction to Foucault's Madness and Civilisation when published in England, endorsing its link to anti-psychiatry ideology. ${ }^{21}$

So contentious were the writings of Scull, Foucault and others in the second half of the twentieth century, that historians since then have criticised their methodologies. ${ }^{22}$ Joseph Melling and Bill Forsythe argued that Foucault displayed some "extravagant historical inaccuracies", such as in his analysis of confinement of the insane in early modern Europe. ${ }^{23}$ Louise Hide described Foucault's study as "brilliant but flawed", such as his arguments about industrial society being increasingly intolerant of its non-productive members so beginning to lock them away in institutions. $^{24}$ Jonathan Andrews and Anne Digby regarded some twentiethcentury historiography as too divorced from wider historical issues and "overly ideologised and unconvincingly theorised" in its approaches to asylums and psychiatry, lacking a firm and comprehensive grounding in archival sources. ${ }^{25}$ Hugh Freeman found no evidence to support Scull's economic and social exclusion model of the asylums. Instead, he found severely ill patients whose relatives had done all they could to contain the situation before seeking admission. ${ }^{26}$ Edward Shorter also criticised historians of the 1960s and 1970s, who

constituted a kind of lost generation in that they have chosen to pursue puffs of smoke, displaying no interest in the question of just what happens historically to make mind and brain go awry. If we wish to tell the story 
of psychiatry empathetically, we must deal with the story of illness rather than arguing that it is a nonstory or that it is unknowable. ${ }^{27}$

Paul Tobia also argued that understanding asylums in depth can only be done by uncovering detailed source material, although that risks creating studies overly detailed and too divorced from wider historical issues. ${ }^{28}$

Another sort of historiography, which has coloured our understanding of psychiatric history, comprises accounts written by medical professionals about their own institutions. ${ }^{29}$ These authors also conveyed biased perspectives, often as culprits of "whiggish" research, according to Juliet Hurn, adopting a "style of history-writing in which it is assumed that scientific progress can be charted through the approach towards an objective scientific truth." 30 Their work tended to be founded on hindsight, comparing the past with scientific evidence and medical standards to which they had aspired during their clinical careers. ${ }^{31}$ They were also judgmental, praising the work of those perceived to have aided "progress" and dismissing others. ${ }^{32}$ They tended to focus on the leadership rather than the patients and on what happened, rather than on analysing processes of why and how things occurred in broader contexts. John Crammer, a psychiatrist who wrote the history of the Buckinghamshire Asylum summarised: "the history of psychiatry was left to medical men with a fondness for anecdote, a reverence for pioneers, and a belief in 'progress'."33

Aware of the many concerns about the nature of the evidence and analysis used in historical studies of mental disorder and institutional care, this study uses standard historical methodology, ${ }^{34}$ and draws extensively on archival and published sources, aiming to achieve a balanced understanding of the asylums, contextualised in the circumstances of the day.

\section{From Broad Theories and Generalisations TO SPECIFICS AND DIVERSITY}

Despite some historical analyses suggesting that the segregation and exclusion of mentally disturbed people was a key rationale for building asylums in rural areas, there are alternative explanations. One was the belief, in line with moral treatment, that the location would provide a healthy environment to benefit recovery and recuperation. Similar principles applied to building rural sanatoria for treating tuberculosis in the 
pre-antibiotic era. Asylums were frequently located on the best siteson a hillside and above urban pollution, and south-facing to maximise sunshine and give shelter from the prevailing winds-to allow employment and leisure in the fresh air. The building of many asylums in the early to mid-nineteenth century was also concurrent with the founding of specialist hospitals, each dedicated to a group of related diseases or a single bodily organ or organ system. In the London area, for example, specialist hospitals opened for eye and ear diseases, bowel problems, cancer and neurological conditions. They raised interest in the diseases on which they focussed, and the knowledge and expertise in treatment which developed in them were gradually adopted by general (physical illness) hospitals, thus becoming part of mainstream medicine and surgery. ${ }^{35}$ There are parallels in the asylums, where the medical leadership sought to better understand the disorders they diagnosed and to find effective treatments, preferably cures.

The architecture of the asylums, the palatial façade of Colney Hatch (Fig. 1.2) or the prison-like central towers at Hanwell (Fig. 1.3) were emblematic of the diversity of the asylums in terms of practices and

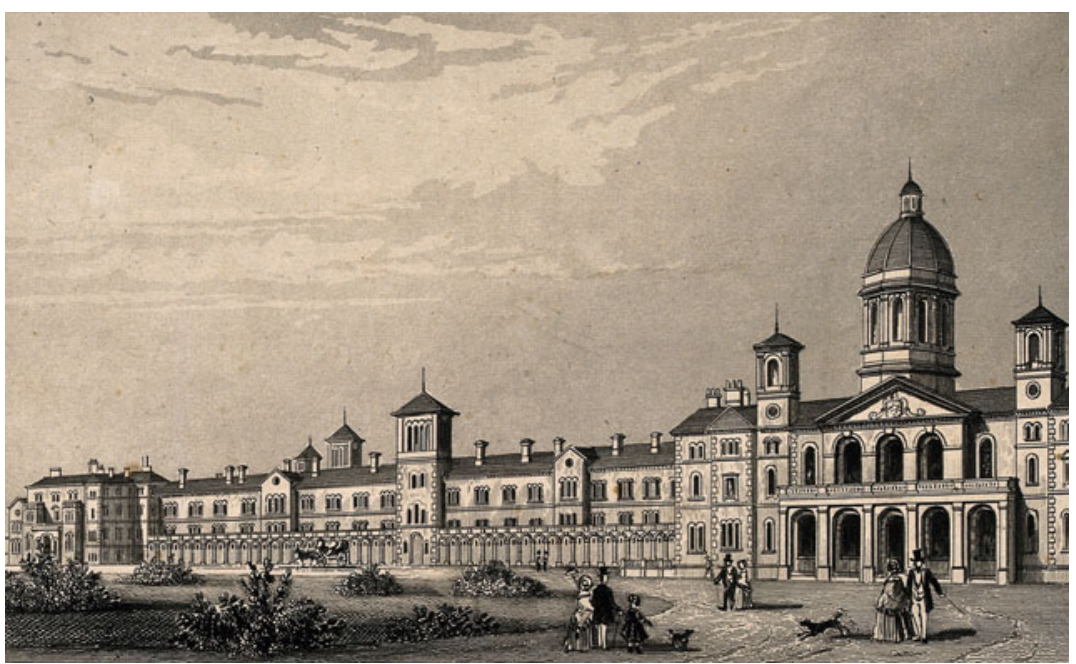

Fig. 1.2 Colney Hatch Lunatic Asylum, Southgate, Middlesex: panoramic view, undated (Wellcome Collection CC BY licence) 


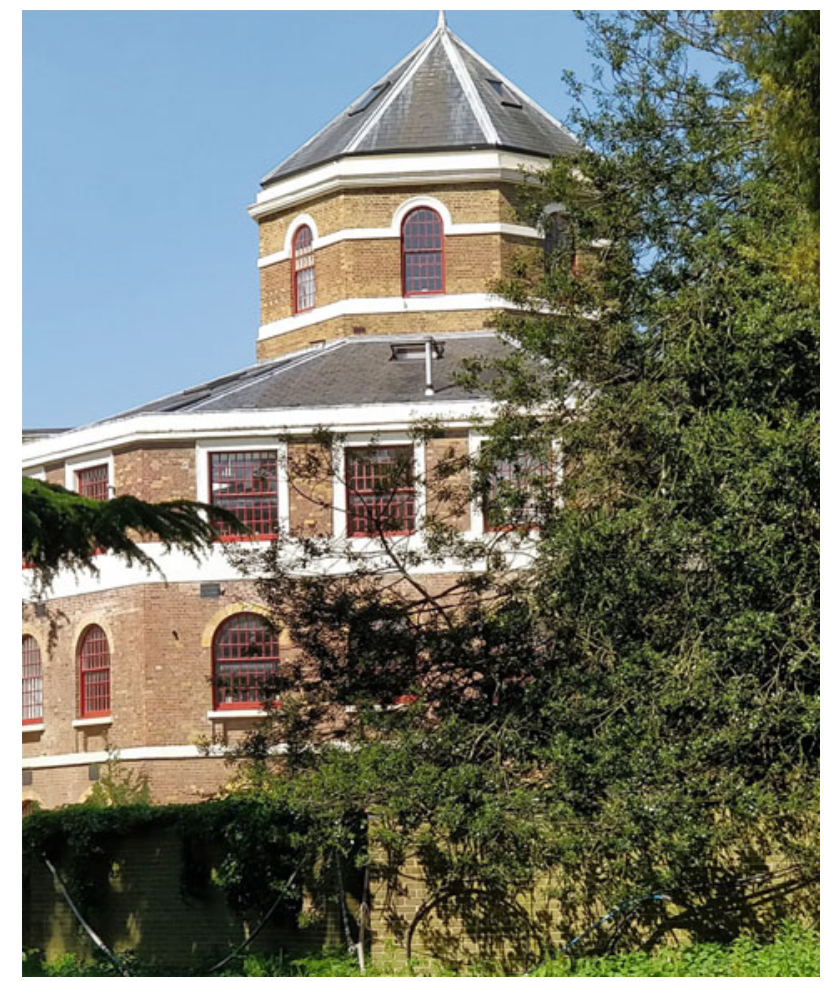

Fig. 1.3 Hanwell Asylum (Photograph by author, 2017)

standards within them. These varied despite the Lunacy Act 1890. The Act mandated legal, financial and organisational structures, and the hierarchy of authority, oversight and regulation stemming from the central government body, the Commissioners in Lunacy until 1914 and the Board of Control ("the Board") thereafter, which had responsibility for civilian asylums in England and Wales. The rigid, legalistic approach of the Lunacy Act also reflected increased societal and legal concerns about public safety, ensuring detention of "dangerous" lunatics while preventing wrongful incarceration of "sane" people. Beyond these requirements, the public generally distanced themselves from happenings inside the asylums, their perspectives reinforced by novels about lunacy 
which tended to emphasise the frightening and the macabre, and rarely encouraged sympathetic interest in the asylums or their occupants. ${ }^{36}$

Historian Roy Porter wrote in 1991 that many dimensions of recent psychiatric institutional history "remain a blank". 37 Since then, understanding of the philosophy, uniformities and diversity of the asylums, has been enhanced by in-depth "hospital biography" investigations into individual asylums, or small groups of them, including in Hampshire, Norfolk, Bristol, Essex, and on the London borders. ${ }^{38}$ These institutional biographies give nuanced insights into asylum organisation, patients, staffing, care and treatment within the wider societal context. In exemplary asylums shortly before the First World War, many patients reportedly undertook manual work appropriate to their pre-admission employment, participated in leisure activities, sports and entertainments, and had leave off the premises, including trial leave before discharge with a meaningful monetary allowance to help cover their personal expenses. Some asylums endeavoured to model their clinical approaches on practices in general hospitals. They placed patients on different wards according to whether they were deemed curable or chronic, used the most up-to-date treatments to ameliorate symptoms, and educated and professionalised their staff. ${ }^{39}$ Diane Carpenter, however, in her comparison of two Hampshire asylums, described the "postcode-lottery" of variability of care and treatment, from custodial to rehabilitative. ${ }^{40}$

Hospital biographies challenge many generalisations made by Scull and Foucault, but they also demonstrate troubling variation, conflicts and mismatches between ideals and reality, intention and implementation, and numerous facets which came together to influence the functions of the asylums and the outcomes for individuals inside them. Mathew Thomson highlighted how individual and collective factors inside and outside the asylum system influenced policy and provision. ${ }^{41}$ Knowledge, understanding and value systems of the medical profession, lawyers, architects, reformers, national and local government, macro- and micro- political networks, and the broader public, all interacted. Together they affected asylum practices and contributed to maintaining the status quo or pacing the speed and mapping the route of any significant change. In histories of psychiatry dedicated to a particular aspect of science, philosophy, psychopathology or individual mode of therapy, "single-issue mythologies" have evolved to explain change or stagnation. ${ }^{42}$ To avoid these mythologies, the multiplicity of threads indicate the need for a multifaceted historiographical approach, digging deep into a range of archives 
and published sources, to reach an understanding about whether, how and when aspects of asylum care altered.

\section{Shell Shock: Historiography and Change}

Regarding mental disorders and psychiatric services at the time of the First World War, historians of psychiatry have focussed on shell shock. Public sympathy for soldiers who became mentally disturbed while serving their country contrasted with fear and stigma concerning mental disorders of civilian pauper lunatics in asylums. The socially entrenched pattern of moral judgement of dividing needy people into "deserving" and "undeserving" was reshaped into provision for war-torn soldiers compared to civilians.

Commentators Anne Rogers and David Pilgrim inferred that shell shock plus industrial fatigue at home combined to "change irrevocably the face of twentieth-century psychiatric services". They proposed that shell shock encouraged environmental theories of aetiology and displaced bio-deterministic ideas: to describe soldiers_-"England's finest blood"as biologically "degenerate" and predisposed to mental disturbance "was logically impossible and tantamount to treason." They linked shell shock to the establishment of out-patient clinics and to neurosis becoming a focus of professional interest, although that was also associated with psychoanalytic theory developing pre-war. ${ }^{43}$

Shell shock may have contributed to re-conceptualising some mental disorders, but overall it stimulated little change in asylum treatment. ${ }^{44}$ If anything, learning arising from the treatment of shell shock could be detrimental to patients with other severe, disabling mental disorders. Methods used to treat shell shock could be harsh, such as "bullying" electric shocks. ${ }^{45}$ Psychological therapies for shell shock, such as cure by suggestion, promoted the idea that patients could control their symptoms, a view which would be inappropriate for people suffering from psychoses, such as schizophrenia, or from organic brain diseases such as general paralysis of the insane (GPI, brain syphilis). ${ }^{46}$ Goals of treating shell shock, to send soldiers back to the front line, meant that medical ethics, humanity and measures of "success" were abstruse when compared to ideals of conventional aims of treatment to promote the health and wellbeing of individuals.

In contrast to Rogers and Pilgrim, Jose Harris and Peter Barham were cautious about attributing change in psychiatry primarily to shell 
shock. Harris raised the question of how far the war itself transformed British society, or merely channelled and accelerated germinating seeds of change sown pre-war when "Britain appeared to be on the cusp of radical change". ${ }^{47}$ Social welfare and universal suffrage, for example, had roots pre-war, but wartime priorities diverted good intentions away from peacetime objectives, and direct implementation ground to a halt. The war, however, generated debate on many aspects of life, including roles and opportunities for women, priorities for reconstruction and the meaning of "civilisation", 48 which informed public attitudes and helped shape the course of post-war policy.

Regarding mental health policy and provision, shell shock was just one factor alongside others, including clinical and scientific research; the psychiatric clinics in Germany envied by psychiatrists in England; and the rise of trade unions and disenchantment with conditions of employment in the asylums. Arguably, The Experiences of an Asylum Doctor by Montagu Lomax, a retired doctor in his late 50s and temporary wartime asylum assistant medical officer at Bracebridge Asylum, Lincolnshire and Prestwich Asylum, Lancashire (1917-1919), had a profound effect on instigating change in the asylums. ${ }^{49}$ For this reason, and as we shall refer to the author, his book and its aftermath several times in the course of the present study, they deserve introduction here. Tim Harding and John Hopton appraised Lomax's work and its outcome. ${ }^{50}$ Lomax was particularly critical of the conditions which he observed at Prestwich, although in his book he did not reveal the identity of the asylum. He advocated more active therapeutic interventions to secure the return of patients to the community, he called for wide-reaching changes in asylum management, and a complete reform of existing mental health legislation. Published post-war, when the public had more emotional energy for considering such matters, it raised public awareness and spearheaded further thought. The psychiatric establishment, however, rejected his descriptions of inhuman, custodial, and antitherapeutic conditions. ${ }^{51}$ Despite publication coinciding with competing economic struggles nationally, likely to deflate interest in asylum patients' welfare, the aftermath of Lomax's exposé was an inquiry into the "administration of public mental hospitals" chaired by Sir Cyril Cobb in 1922. This led to the appointment of the 1924-1926 Royal Commission on Lunacy and Mental Disorder and to the enactment of the more therapeutically orientated Mental Treatment Act $1930 .{ }^{52}$ 


\section{Placing the Patients Centre Stage}

Some historians of psychiatry, as Roy Porter advocated, have succeeded in placing patients centre stage in their narratives. ${ }^{53}$ Louise Hide's study about gender and class in asylums between 1890 and 1914 and Paul Tobia's study of the Bristol Lunatic asylum were both bottom-up and top-down, valuing the lives and experiences of patients and those in direct contact with them, as well as those in authority in the asylum hierarchy up to national level. ${ }^{54}$ Allan Beveridge analysed 1000 letters written by patients at the Royal Edinburgh Asylum (1873-1908) which were retained by the authorities rather than sent to the addressee. A complex picture emerged in their accounts, which included both humanity and coercion. Many patients spoke warmly of the asylum and its staff and frequently thanked the medical superintendent for his kindness and concern. Some patients, rejected by family and friends, made some sort of life for themselves within the asylum which was more tolerant of their behaviour than the society outside. Letters, like many other single classes of document from the asylum world, have limitations, but Beveridge concluded that the contents should militate against painting too crude a picture of the asylum with staff in the guise of oppressors and inmates as innocent victims. ${ }^{55}$ His conclusions contrasted with studies which create an overwhelmingly negative image of the asylums, such as those by Scull. ${ }^{56}$

Peter Barham also wove individual life stories into his history of shell shock, Forgotten Lunatics of the Great War. He placed the sufferers' mental disturbances in the context of their lives and the lives of their families and community, giving voice to their personal experiences. In contrast to the forgotten soldier patients during the war, civilian patients in the lunatic asylums were almost invisible and usually without a voice. Barham described his research experience, that "fossicking in the archival undergrowth frequently yields scraps that, once juxtaposed, deliver startling insights into what was at stake" for individuals. ${ }^{57}$ The same was true when researching this study of civilians, which, like Barham's and Beveridge's work, aims to tell the patients' stories and how their needs were, or were not, met.

A variety of bottom-up sources are available to historians of asylums in the early twentieth century. Within individual asylum records, material written by patients, their families and friends can be found pasted into clinical notes and committee minutes. Some documents are positive, 
including letters of thanks, but more relate to disputes about treatment, thefts, escapes, discharge and money, and other unfavourable aspects of asylum life. As in Beveridge's study, some accounts by patients derive from un-posted, asylum-censored letters. Regarding patients' letters to friends and family, staff had authority to read them. Staff justified their probing in this way as a means of finding out about their patients in order to help them, but this probably reflected, and caused, a lack of trust and face to face conversation between patients and staff. Patients who were aware of the censorship of their letters might also have adjusted their content and tone.

In contrast to personal letters, the Lunacy Act stipulated that letters from patients to the authorities who oversaw their certification and care should be forwarded unopened, but this correspondence was often destroyed after being dealt with. ${ }^{58} \mathrm{~A}$ few patients wrote memoirs. Whereas letter writing is influenced according to who the recipient might be, memoirs can be shaped by time between the experience and the writing, affected by personal reflection, changing knowledge and social expectations giving new emphases. Diaries, generally written for the authors themselves, are the least likely to be tailored to an anticipated external readership. No diaries, however, were identified while researching the present study. Another source of patients' views was their evidence to the Cobb Inquiry as a result of Lomax's book. ${ }^{59}$

Some of the patient vignettes used in this study were identified serendipitously in clinical records or committee minutes. Others derived from a sample I gathered of 600 civilian patients from the national registers of asylum admission and discharge (1913-1918). ${ }^{60}$ The sample consisted of every thirtieth patient (the last entry on each page) in the register. Each entry recorded the asylum's name, and patient's name, gender, dates of admission and outcome (recovered, relieved, not improved, died), but not age, date of birth, diagnosis or other clinical information. The method ensured that the sample was clinically, socially and demographically un-biased. In total, 58 of the 600 patients were admitted to Colney Hatch, Claybury, Napsbury and Hanwell. Detailed social and clinical data were sought for them, with the aim of analysing the reasons for their admission and their "journey" through the institution. 


\section{Standards of Care and How to Measure Them}

Several historians have attempted to ascertain the standards of care achieved in asylums. Carpenter concluded that "basic determinants of the quality of life" for patients in the Hampshire asylums pre-war were "preferable to its alternatives": diet, cleanliness, personal hygiene and clothing, all compared reasonably with poorer private dwellings and the workhouse. Other living conditions were similar to many poorer homes, such as gas lighting, open fires, no electricity and lack of privacy. ${ }^{61}$ Kathleen Jones, who investigated mainly social and legal aspects of mental health policy and practice, commented that for asylum patients who worked during the day and took part in social activities in evenings and weekends, "it was a full life - often much more so than their life outside." 62 She did not state a particular period to which this referred, or whether it was reality at times of greatest austerity.

Standards and quality of care, the parameters which underpinned them, and how and why they changed, often for the worse during the war, are explored thematically in this book. The Board had responsibility for setting and monitoring standards and determining the adequacy of the care provided. It benchmarked asylums against ideals and expectations which were often inferred from its annual reports and letters and circulars of guidance, rather than stated systematically. During the war, with pressure on resources and an assumption of compromise, the Board modified its ratings and accepted lower standards. Its methods of assessing asylum standards were also unconvincing: inspectors focussed on documentation and basic, easily observable physical matters, such as cleanliness. Less tangible and more complex human needs ${ }^{63}$ were rarely assessed in a balanced way such as by talking frankly to patients. Patient-derived data is hard to identify and neither Carpenter nor Jones reflected directly on patients' perspectives of their treatment or quality of life.

Developments since the First World War in setting standards and parameters to evaluate healthcare quality can provide useful tools in structuring an historical analysis. Formal mechanisms for conceptualising and measuring healthcare standards originated in the United States of America in the 1930s, aligned to the insurance-based healthcare system. ${ }^{64}$ Louis Reed and Dean Clark in 1941 defined healthcare quality according to the scope, quality, quantity and continuity of care, and coordination with social services. ${ }^{65}$ In the 1950 s, Mindel Sheps acknowledged the intangible nature of healthcare quality, and its assessors tendency to 
focus on correcting abuses and setting minimum standards, rather than achieving excellence, ${ }^{66}$ much as the Board did. Ideas about standards obtained a wider organisational acceptance from the 1960s, based on the work of Avedis Donabedian. Donabedian ${ }^{67}$ wrote about the need to define dimensions of quality before specifying what constitutes "goodness" or "badness". However, since stakeholders value quality according to their own interests, defining dimensions is complex. Value for money, system capacity and outcome of treatment, for example, hold different salience for patients, policy makers, financial providers and clinical staff, ${ }^{68}$ resulting in conflicting priorities underpinning distribution and utilisation of resources.

Additional concepts derived from new organising categories about mental health services, such as costs, risks, needs and values, and their use in historical analysis were discussed by John Turner et al. ${ }^{69} \mathrm{He}$ recommended their incorporation into historical research about modern mental health services, but the concepts are also useful markers for studying services in the more distant past. The Care Quality Commission, today's independent regulator of all health and social care services in England, aims to judge whether services are safe, caring, effective, responsive and well led, based on criteria founded on a human rights agenda. ${ }^{70}$ Reports of asylum inspectors a century ago reveal their concerns on similar human matters, such as dignity, meaningful life, sense of community, as much personal freedom as possible, and contact with family and the outside world. Achieving a consensus regarding standards of healthcare is challenging. Although there was no consensus for the asylums, awareness of the multiple components of standard setting can assist with focussing historical analysis on a range of issues concerning formulating, prioritising and evaluating earlier standards.

\section{The Language of the Asylums}

There are many other methodological considerations when writing the history of psychiatry and its institutions, but the use of language looms large. The term "asylum" was itself was controversial. In 1841, a handful of psychiatrists proposed replacing it with "hospital". ${ }^{71}$ In 1908, the Royal Commission on "the feeble-minded" also recommended the substitution. It reasoned that the word asylum was misleading as it "savours of the mere detention of extreme cases". Treatment was the goal, so they 
should be called hospitals. ${ }^{72}$ The term was already permitted for privatelyrun and military psychiatric establishments. A name change alone would not change practice, but it had the potential to influence expectations about treatment and recovery from mental disorders.

Attitudes towards people suffering from mental disorders were expressed by the language of public and official discourse. The public referred to asylum staff as "keepers", more in line with prisons or zoos than hospitals. ${ }^{73}$ An "escaped" patient might be described as "at large", a term generally used to refer to a criminal or dangerous animal, and a resident staff member might be "absent without leave", a military term. ${ }^{74}$ Patients conflated their asylum experience with prison jargon, substituting seclusion in a side-room or "padded" room with solitary confinement in a "cell". 75 The Lunacy Act designated asylum patients "pauper lunatics", the "pauper" label adding an extra layer of stigma to their "lunacy". Much of the Act's vocabulary resembled that of prisons and workhouses, such as detention, parole, escape and recapture. Nevertheless, the Act used the word "patient" or "lunatic", reserving the more derogatory word "inmate" for occupants of workhouses, although "inmates" continued to appear in asylum committee minutes during the war years when referring to people under their care. ${ }^{76}$ Overall, deprecatory language articulated apprehension and fear of asylums and mentally disturbed people, and lack of empathy and compassion, distancing those outside from the human needs of those within.

Another word, "control", commonly features in historiography of asylum practice. The Lunacy Act used the word "control" in several contexts: concerning the administrative control of asylums; when a person in the community was "not under proper care and control, or is cruelly treated"; and for defining the need for urgent admission to a workhouse when behaviour due to a mental disorder risked causing direct harm to the disturbed individual or to others. ${ }^{77}$ Control can be an emotive word with multiple connotations which beg the question of who controlled whom, and how and why. The word itself gives no indication of the rationale (such as to protect the patient or others) or the means (humane or coercive) to achieve it, but critics interpret it to imply abuse. Scull described the asylum as "the new apparatus for the social control of the mad", with control the primary objective. ${ }^{78}$ This contrasts with the stated aims of the Act for asylums to provide "care and treatment", 79 which inevitably included control of a patient's disturbed behaviour. The aims, means 
and outcomes of therapeutic and harmful control of asylum patients, are recurring themes in this book.

How to deal sensitively with stigmatising terminology is another conundrum for historians. This is particularly problematic in the history of psychiatry as language associated with mental disorders changes in attempts to discard associated stigmata and to dispel prejudice and discrimination. These attempts often fail: new names selected to replace them tend to acquire old humiliations, while the old language can linger colloquially and in official documents and debates, including in parliament. ${ }^{80}$ Old technical terms which perpetuate may acquire broadly derogatory meanings, such as the words imbecile, idiot, spastic and mongol, and may indicate out-dated attitudes of the speakers.

Many historians, including Foucault, Porter and Scull loosely referred to "madness", a generic term for mental symptoms. ${ }^{81}$ This may have been appropriate to earlier centuries but was outdated by Edwardian times when "insanity" or "lunacy" were the characteristic generic terms. ${ }^{82}$ For historians of psychiatry, antiquated terms may best help understand highs and lows and obstacles and opportunities facing those who tried to cope with, survive in, or improve institutions and clinical practices. In this book antiquated term are therefore used, but with respect for patients and with the intention of illuminating how they fared at the hands of the asylum system.

Over the last century, the meaning of much psychiatric terminology shifted. "Mania", for example, as used in asylums a century ago, meant any mental disturbance characterised by overactivity. In contrast, today it refers specifically to a diagnosis of bipolar disorder. "Dementia", a chronic deterioration of intellectual and social function, was used to refer to GPI or chronic stages of schizophrenia. Dementia could also be categorised as primary, secondary or senile, but the word senile carried multiple meanings and assumptions relating to chronological age, ageing, old age or conditions assumed to be age-related.

Another pair of words, "illness" and "disease", have influenced the choice of language in this book. Eric Cassell, a public health physician, used the word "illness" to mean "what the patient feels when he goes to the doctor", and "disease", "what he has on the way home from the doctor's office." 83 From an anthropological viewpoint, a disease is an independent entity which has specific properties and a recurring identity in whichever setting it appears, and illness relates to the personal experience of it. A disease is assumed to comprise a universal "syndrome", with 
pathology, causation, symptoms and signs, natural history, treatment and prognosis similar in whatever individual, culture or ethnicity it occurs. ${ }^{84}$ If, as in mental disorders, brain disease may be undetectable, the boundaries between illness and disease can be blurred. With lack of clarity and inconsistency in some source material, I have frequently used the deliberately vague terms "disorder", "disturbance" or "distress", meaning a disruption of the individual's usual mental and bodily function.

Some diseases and illnesses can be identified historically if adequate evidence is available. Evidence may be found by careful examination of patients' clinical notes, revealing history, symptoms and physical and mental state examinations. For psychiatric disorders, ascertaining the patterns of symptoms over time is invaluable for determining the type of disorder. Many First World War asylum records allow this sort of clinical analysis. However, since precise psychiatric diagnostic criteria and illness classifications continue to be disputed and to change, detailed "retrospective diagnosis" comparisons with twenty-first century terminology lack meaning. Nevertheless, there is room to construct a "working diagnosis" relating to a class of disorders. A working diagnosis can assist in clarifying other historical evidence, such as about detention, recovery or chronicity requiring long term support. "Translations" into current terminology are sometimes given to enhance understanding for a readership more familiar with twenty-first century mental health vocabulary.

Other less contentious areas of asylum terminology, which nevertheless still require clarification, are professional designations, such as "psychiatrist" and "attendant". The Royal Society of Medicine established a "Section of Psychiatry" in 1912 and "psychiatrist", referring to a medical doctor who specialised in mental illness, replaced the older term "alienist", meaning a doctor who treated "mental alienation". 85 The term psychiatrist gained acceptance in the early twentieth century and is used in this book. Concerning asylum ward staff, "attendants" were generally male and "nurses" female, but this could be inconsistent, such as in the title of the textbook for both, the Handbook for the Instruction of Attendants on the Insane, a general training manual for asylum ward staff. 86 Historians have adopted various ways to deal with this gendered language, such as using the generic term "asylum nurse". ${ }^{87}$ In this study, as far as possible, I have kept the terminology as it appears in archival sources, but when referring to the combined male and female ward workforce, I have generally called them "ward staff". 


\section{Other Methodological Considerations}

Four asylums provide the core, in depth source material for this study: Claybury, Colney Hatch, Hanwell and Napsbury. Claybury, Colney Hatch and Hanwell were London County Council (LCC) asylums, and Napsbury served the county of Middlesex, particularly the more urbanised part, coterminous with the LCC's northern administrative border. Despite the distance between any two of these asylums being under 25 miles by road, each had a different institutional wartime footprint. Part of Napsbury was taken over as a war hospital in 1915, the rest in 1916. Colney Hatch had a large proportion of patients from abroad, including Belgian refugees, prisoners of war, interned foreign nationals, and Jewish people from the East End of London. ${ }^{88}$ Claybury lost its prestigious scientific research laboratories during the war and suffered extraordinarily high death rates in 1917-1918. ${ }^{89}$ Hanwell steered a middle path, receiving hundreds of patients from other asylums vacated for military use, but it experienced neither the diverse ethnic mix of Colney Hatch nor the extreme death rates at Claybury.

Each asylum has an extensive, but not too unwieldy, range of archived records. They provide a flavour of the challenges, contrasts and commonalities of each in a context of prolonged austerity. Some have unique records which were not preserved by the others. Only Colney Hatch, for example, has records of staff salaries and wages, ${ }^{90}$ and only Hanwell has note books of staff misdemeanours. ${ }^{91}$ Management committee minutes vary in their detail, such as Claybury's which list issues raised by the medical superintendent without giving particulars, contrasting with the others which generally record associated discussions. ${ }^{92}$ Reasons for degree of thoroughness of minute keeping were not revealed, but they may have included staff availability to take minutes and to type them, or the wishes of the medical superintendent and management committee, but some give an impression of concealing problems.

Colney Hatch archives include albums of photographs of patients taken for identification purposes shortly after admission. ${ }^{93}$ Photographing patients was a common practice in many asylums in the early twentieth century, but the images have received relatively little attention by historians of medicine. Katherine Rawling argued that examining the visual patient record can enhance, and even challenge, established histories of mental illness and medico-psychiatric practice: they may give clues to the doctor-patient encounter, to diagnosis and treatment, and to the 
patient's experience. ${ }^{94}$ In some asylums, photographs of patients resembled police mug-shots, ${ }^{95}$ but those from Colney Hatch are varied. They demonstrate aspects of mental and physical health, and attitudes and attire, thus indicating something of the patient's experience. Ludmilla Jordanova recommends that images should be "integral parts of historical arguments" and that historians must be particularly aware of their ethical obligations to their sources, being reflective, accurate, compassionate and responsible. ${ }^{96}$ Regarding ethics, all the images of patients conform to the 100-year rule for confidentiality of personal archives. In addition to this, to help preserve anonymity, surnames are not used when discussing them. First names are used to engender a sense of empathy and identification with them, to emphasise that each was a human being whose experience in the asylum we are attempting to understand. The images may also help reveal how the staff-doctors and others-would begin to understand their patients: "Much can be learned" staff were instructed, "from how a person looks, and the expression of the face, the attitude, the dress and other visible signs of a person's emotional and mental state."97 The images also need to be interpreted in the context of the experience of having one's photograph taken. Some patients may never have been photographed before, so might have found the process unsettling or amusing, although in general, posing for a photograph was a formal event, with facial expressions usually emotionally neutral. Thus, patients in asylum photographs who are smiling may have had an abnormal state of mind, or the image reflected their interactions with the photographer or other staff. As with other sources, there are multiple layers of interpretation.

Another aspect of asylum archives concerns the historical usefulness of clinical notes. Tobia regarded them as bearing the "imprint and prejudices" of the asylum staff, ${ }^{98}$ and Andrews suggested that clinical notes "convey more about the preoccupations of the asylum's medical regime than about the patients and their histories". 99 Although clinical notes need to be read critically using knowledge of prevailing medical theories and social views, Tobia and Andrews may have overestimated their subjectivity. Medical notes comprised two main components. First, demographic data plus biographical information, clinical history and examination which were largely objective and collected in a standard way. Second, the medical officer's interpretation of the findings to identify causes, formulate treatment plans and consider prognosis. The medical officer making the notes would have been aware that the Board might scrutinise them during 
an inspection or the medical superintendent might peruse them when reviewing the patient sometime later. ${ }^{100}$ The doctor compiling them would therefore have had a vested interest in demonstrating his (rarely, her) expertise and clinical objectivity in order to enhance his professional reputation. The overall uniformity of clinical note keeping, at least within the asylums investigated in the present study, suggests little scope for personal views.

Archives relating specifically to the four asylums focussed on in this book complement national records but cannot be assumed to be representative of asylums elsewhere across England and Wales. Eight of the nine LCC lunatic asylums had over 2000 beds each, making them larger than most others nationally. In addition, in most lunatic asylums, a significant proportion of patients had a "mental deficiency" (later known as learning disability). This was less so in the London area where the Metropolitan Asylums Board managed many health and welfare institutions, including those for mental deficiency, separate from the lunatic asylums which were the direct responsibility of the LCC. ${ }^{101}$ Regarding other effects of wartime contributing to making London's asylums unrepresentative, this is hard to ascertain: according to Stefan Goebel and Jerry White, except for air raids, revisited from the standpoint of the Second World War, First World War London has had relatively little historical analysis. ${ }^{102}$ The German bombing raids on London, initially by Zeppelins and later by Gotha bombers, were more intense than in other parts of the country, and induced fear and panic in civilians, but how that affected asylum admissions and the patients and staff within them, is less clear. ${ }^{103}$

Despite the differences, the four asylums did have commonalities with those elsewhere. Their patients suffered the same range of mental and physical disorders. They were all subject to the Lunacy Act, regulation by the Board of Control, and pressures to release staff to serve in the war and to provide beds for physically and mentally injured soldiers. Scotland had separate legislation and some of their asylum practices were more liberal than those south of the border. Scottish records can shed light on happenings in English and Welsh public asylums, as can developments internationally and sources relating to private and military mental hospitals.

In addition to archives relating to each asylum, the Board's records include minutes, unpublished documents and published annual reports. The annual reports have extensive statistical tables about asylums, including disease and death, but they are far from fool-proof. Their focus 
and extent vary from year to year and administrative categories can be confusing: some tables, for example, include all patients detained under the Lunacy Act, others only those in public asylums. Data were collected according to information priorities, and during the war many details were abandoned due to lack of staff to gather, sort, collate and transcribe them.

Investigating the period 1914-1918 has pros and cons. One con is that much record keeping was abandoned due to staff shortages. A major pro is that archive sources are now beyond the 100-year rule for personal information. Many records, however, have been destroyed. The Board discarded records they considered obsolete, such as letters of complaint, registers of seclusion and restraint, and notices of discharge and death. ${ }^{104}$ Survival of other Board records was partly governed by rules about disposing of papers for which preservation for the public record could not be justified. ${ }^{105}$ In addition, with space for storing notes at a premium, and wartime paper shortages, some Board and LCC records were pulped. ${ }^{106}$ Further destruction took place later. Three-hundred metres of files stored below King Charles Street, Westminster, became unusable by the 1930s: the air "was foul and stagnant" and periodically the vaults flooded necessitating using duck boards to avoid having "to wade in water to get to the shelving". ${ }^{107}$ Later, the archiving of records from individual asylums was hardly systematic: Dawn Galer, archivist at the Redbridge Heritage Centre, recalled that most records from Claybury were incinerated when the hospital closed in 1997.

Overall, archives and published sources are available which relate to many aspects of the asylums, including the lives of patients and staff. To best understand what happened to the people, and to attempt to decipher how the asylums functioned during the war years, this book takes a thematic approach. The narrative and argument are clearest when beginning with the context of the relatively fixed infrastructure of the asylums (Chapter 2). The raison d'être of the asylums, and the central theme of this book, the people who suffered from mental disorders, their routes into the asylums, their difficulties, care and treatments, are discussed after that (Chapter 3). This is followed by exploring the challenges of staffing the asylums (Chapter 4) and obtaining goods and consumables to satisfy daily living needs during the war (Chapter 5). These themes come together to create an understanding of the patients' daily lives (Chapter 6) and to contextualise and inform the narrative of how physical illness, particularly potentially avoidable infectious diseases (Chapter 7), 
and "accidents" and suicides and other undesirable outcomes (Chapter 8), affected the lives of those in the institutions.

\section{Notes}

1. Edward Shorter, A History of Psychiatry (New York: John Wiley and Sons Ltd, 1997), 33.

2. Richard Hunter and Ida Macalpine, Psychiatry for the Poor: 1851 Colney Hatch Asylum-Friern Hospital 1973: A Medical and Social History (London: Dawsons of Pall Mall, 1974), 158.

3. Hunter and Macalpine, Psychiatry for the Poor, 50.

4. Hugh Freeman, "Psychiatry in Britain c.1900," History of Psychiatry 21 (2010): 312-24, 313.

5. Lunacy Act 1845 section 57.

6. Lord Ashley, Earl of Shaftesbury, in: Treatment of Insane Persons in England and Wales. Hansard HC Deb 06 June 1845 vol 81 ccl80-202.

7. First Annual Report of the Board of Control, for the Year 1914 (London: HMSO, 1916) (BoC AR 1914), Part 1, 4.

8. BoC AR 1914, Part 2, 29-30, 32-33.

9. Freeman, "Psychiatry in Britain": 313.

10. BoC AR 1914, Part 1, 8 .

11. Steven Cherry, Mental Healthcare in Modern England: The Norfolk Asylum/St. Andrews Hospital 1810-1998 (Woodbridge, Suffolk: Boydell Press, 2003), 144-45, 170.

12. Peter Barham, Forgotten Lunatics of the Great War (New Haven and London: Yale University Press, 2004); Suzie Grogan, Shell Shocked Britain: The First World War's Legacy for Britain's Mental Health (Yorkshire: Pen and Sword Books, 2014).

13. E.g. John Crammer, "Extraordinary Deaths of Asylum Inpatients During the 1914-1918 War," Medical History 36 (1992): 430-41; Cherry, Mental Healthcare; Diana Gittins, Madness in Its Place: Narratives of Severalls Hospital, 1913-1997 (London: Routledge, 1998).

14. Andrew Scull, The Most Solitary of Afflictions: Madness and Society in Britain, 1700-1900 (New Haven: Yale University Press, 1993), 1.

15. Michel Foucault, Madness and Civilization: A History of Insanity in the Age of Reason (tr. Richard Howard) (London: Routledge, 1989), 4.

16. Lunatic Asylums and Pauper Lunatics Bill. Hansard HL Deb 29 July $1845 \mathrm{vol} 82 \mathrm{ccll} 186-93$.

17. The official report of all parliamentary debates.

18. Andrew Scull, Decarceration: Community Treatment and the Deviant: $A$ Radical View (New Jersey: Prentice Hall, 1977), 25-27. 
19. Scull, Solitary, 370.

20. Michel Foucault, Folie et Déraison: Histoire de la Folie à l'Âge Classique (Paris: Union Générale d'Éditions, 1961); Ronald "RD" Laing, The Divided Self: An Existential Study in Sanity and Madness (Harmondsworth: Penguin, 1960); Thomas Szasz, The Myth of Mental Illness: Foundations of a Theory of Personal Conduct (London: Paladin, 1961); Erving Goffman, Asylums: Essays on the Social Situation of Mental Patients and Other Inmates (1961; Harmondsworth: Penguin, 1980).

21. David Cooper, "Introduction," vii-ix, in Foucault, Madness and Civilisation (1989).

22. Paul Tobia, "The Patients of the Bristol Lunatic Asylum in the Nineteenth Century" (PhD thesis, University of the West of England, 2017), https://eprints.uwe.ac.uk/29359, 11.

23. Joseph Melling and Bill Forsythe, The Politics of Madness: The State, Insanity and Society in England, 1845-1914 (London and New York: Routledge, 2006), 3.

24. Louise Hide, Gender and Class in English Asylums, 1890-1914 (London: Palgrave Macmillan 2014), 5.

25. Jonathan Andrews and Anne Digby, "Gender and Class in the Historiography of British and Irish Psychiatry," 7-44, in Sex and Seclusion, Class and Custody: Perspectives on Gender and Class in the History of British and Irish Psychiatry, ed. Jonathan Andrews and Anne Digby (New York: Rodopi, 2005), 13.

26. Hugh Freeman, "Psychiatry and the State in Britain," 116-40, in Psychiatric Cultures Compared: Psychiatry and Mental Health Care in the Twentieth Century: Comparisons and Approaches, ed. Marijke Gijswijt-Hofstra, Harry Oosterhuis, Joost Vijselaar and Hugh Freeman (Amsterdam: Amsterdam University Press, 2005), 119.

27. Shorter, A History of Psychiatry, 49.

28. Tobia, "Bristol Lunatic Asylum": 20; Andrews and Digby, "Gender and Class": 13.

29. E.g. Hunter and Macalpine, Psychiatry for the Poor.

30. Juliet Hurn, "The History of General Paralysis of the Insane in Britain, 1830 to $1950 "$ (PhD thesis, University of London, 1998), https://dis covery.ucl.ac.uk/1349281/1/339949.pdf, 7-8.

31. Claire Hilton, "Psychiatry Past and Present: Do We Need History?" BJPsych Bulletin 43 (2019): 126-30.

32. Hurn, "History of General Paralysis": 7-8.

33. John Crammer, Asylum History: Buckinghamshire County Pauper Lunatic Asylum-St John's (London: Gaskell, 1990), ix.

34. E.g. Simon Gunn and Lucy Faire (eds), Research Methods for History (Edinburgh: Edinburgh University Press, 2016). 
35. George Rosen, The Specialization of Medicine with Particular Reference to Ophthalmology (New York: Froben Press, 1944).

36. Valerie Pedlar, The Most Dreadful Visitation: Male Madness in Victorian Fiction (Liverpool: Liverpool University Press, 2006); Fiona Subotsky, Dracula for Doctors: Medical Facts and Gothic Fantasies (Cambridge: Cambridge University Press, 2019).

37. Roy Porter, "History of Psychiatry in Britain," History of Psychiatry 2 (1991): 271-79, 277.

38. Diane Carpenter, "AAbove All a Patient Should Never Be Terrified': An Examination of Mental Health Care and Treatment in Hampshire 1845-1914" (PhD thesis, University of Portsmouth, 2010), https://researchportal.port.ac.uk/portal/files/5877161/Diane_ Carpenter_PhD_Thesis_2010.pdf, 120; Cherry, Mental Healthcare; Tobia, "Bristol Lunatic Asylum"; Gittins, Madness; Hide, Gender and Class.

39. Hide, Gender and Class, 171.

40. Carpenter, “'Above All”: 230-31.

41. Mathew Thomson, The Problem of Mental Deficiency: Eugenics, Democracy, and Social Policy in Britain c.1870-1959 (Oxford: Clarendon Press, 1998): 3-4, 6 .

42. German Berrios, The History of Mental Symptoms: Descriptive Psychopathology since the Nineteenth Century (Cambridge: Cambridge University Press, 1996); FE James, "Insulin Treatment in Psychiatry," History of Psychiatry 3 (1992): 221-35; Edward Shorter and David Healy, Shock Therapy: A History of Electroconvulsive Treatment in Mental Illness (London: Rutgers University Press, 2007); John Turner, Rhodri Hayward, Katherine Angel, Bill Fulford, John Hall, Christopher Millard, et al., "The History of Mental Health Services in Modern England: Practitioner Memories and the Direction of Future Research," Medical History 59 (2015): 599-624.

43. Anne Rogers and David Pilgrim, Mental Health Policy in Britain (London: Macmillan Press Ltd, 1996), 57-58.

44. Freeman, "Psychiatry and the State": 120.

45. Harold Merskey, "Shell Shock," 245-67, in 150 Years of British Psychiatry 1841-1991, ed. German Berrios and Hugh Freeman (London: Gaskell, 1991), 264.

46. Charles Myers, "A Contribution to the Study of Shell Shock," Lancet 13 February 1915: 316-20; Merskey, "Shell Shock": 246-47, 264.

47. Jose Harris, Private Lives, Public Spirit: Britain 1870-1914 (New York: Oxford University Press, 1993), 1, 251-52; Barham, Forgotten Lunatics, 3 .

48. Tracy Loughran, Shell Shock and Medical Culture in First World War Britain (Cambridge: Cambridge University Press, 2017), 26-27. 
49. Anon. "Montagu Lomax MRCS Eng, LRCP Edin," Lancet 25 March 1933,668 .

50. Tim Harding, “Not Worth Powder and Shot': A Reappraisal of Montagu Lomax's Contribution to Mental Health Reform," BJPsych 156 (1990): 180-87; John Hopton, "Prestwich Hospital in the 20th Century: A Case Study of Slow and Uneven Progress in the Development of Psychiatric Care," History of Psychiatry 10 (1999): 349-69.

51. Montagu Lomax, The Experiences of an Asylum Doctor (London: Allen and Unwin, 1921); Harding, "Not Worth Powder and Shot": 180.

52. Ministry of Health $(\mathrm{MoH})$, Report of the Committee on Administration of Public Mental Hospitals Cmd. 1730 (Chairman: Sir Cyril Cobb) (London: HMSO, 1922); Report of the Royal Commission on Lunacy and Mental Disorder (Macmillan Commission) (London: HMSO, 1926); Hopton, "Prestwich Hospital in the 20th Century": 356.

53. Alice Brumby, “'A Painful and Disagreeable Position': Rediscovering Patient Narratives and Evaluating the Difference Between Policy and Experience for Institutionalized Veterans with Mental Disabilities, 19241931," First World War Studies 6 (2015): 37-55; Roy Porter, "The Patient's View: Doing Medical History from Below," Theory and Society 14 (1985): 175-98.

54. Hide, Gender and Class; Tobia, "Bristol Lunatic Asylum."

55. Allan Beveridge, "Life in the Asylum: Patients' Letters from Morningside, 1873-1908," History of Psychiatry 9 (1998): 431-69, 465.

56. Scull, Solitary.

57. Barham, Forgotten Lunatics, 7.

58. Lunacy Act 1890, section 41; BoC, "Orders for Destruction of Documents," 31 March 1909 MH 51/723 TNA.

59. MoH, Committee on Administration.

60. BoC, Patients admission registers: Rate aided admissions 1913-1918 MH 94/48-53 TNA.

61. Carpenter, "'Above All"”: 67, 166.

62. Kathleen Jones, “The Culture of the Mental Hospital," 17-27, in 150 Years of British Psychiatry ed. Berrios and Freeman, 24.

63. E.g. Abraham Maslow, "A Theory of Human Motivation," Psychological Review 50 (1943): 370-96.

64. Roger Lee and Lewis Jones, The Fundamentals of Good Medical Care (Chicago: Chicago University Press, 1933).

65. Louis Reed and Dean Clark, "Appraising Public Medical Services," American Journal of Public Health and the Nation's Health 31 (1941): 421-30.

66. Mindel Sheps, “Approaches to the Quality of Hospital Care," Public Health Reports 70 (1955): 877-86, 883-84. 
67. Avedis Donabedian, "Evaluating the Quality of Medical Care," Milbank Memorial Fund Quarterly 44 (suppl) (1966): 166-206.

68. Veena Raleigh and Catherine Foot, Getting the Measure of Quality: Opportunities and Challenges (London: King's Fund, 2010), 5; World Health Organisation, Mental Health Policy and Service Guidance Package: Quality Improvement for Mental Health (Geneva: WHO, 2003), 2.

69. Turner et al. "History of Mental Health Services."

70. Care Quality Commission, "The Five Key Questions We Ask," https:// www.cqc.org.uk/what-we-do/how-we-do-our-job/five-key-questionswe-ask.

71. Thomas Bewley, Madness to Mental Illness: A History of the Royal College of Psychiatrists (London: RCPsych Publications, 2008), 11.

72. LCC LCC/MIN/00583 Meeting, 18 December 1917, 234, citing Royal Commission on the Care and Control of the Feeble-Minded Cd. 4202 (Radnor Report) (London: HMSO, 1908) LMA.

73. William Stoddart, Mental Nursing (London: Scientific Press, 1916), 9.

74. BoC, Representative case papers of patients: Eliza Garratt, Daily Sketch 21 May 1923 MH 85/62 TNA; Hanwell LCC/MIN/01096 Meeting, 28 August 1916, 156 LMA; "absent without leave," Oxford English Dictionary Online (Oxford University Press, 2020) https://www.oed. $\mathrm{com} /$ view/Entry/647? rskey=bxHyz2\&result=1 \&isAdvanced=false\#eid 5286197.

75. D Davidson, Remembrances of a Religio-Maniac (Stratford-on-Avon: Shakespeare Press, 1912), 50-51.

76. Lunacy Act 1890 section 24 (1); e.g. LCC LCC/MIN/00583 Meeting, 30 October 1917, 143 LMA.

77. Lunacy Act 1890 section 169 (3); 13 (1); 21 (1).

78. Scull, Solitary, 1-2.

79. Lunacy Act 1890 Form 8.

80. Lunatic Asylum, Worplesdon. Hansard HC Deb 24 June 1937 vol 325 cc1369-70.

81. Roy Porter, A Social History of Madness: Stories of the Insane (London: Weidenfeld and Nicolson, 1989); Foucault, Madness and Civilisation; Roy Porter, Madness: A Brief History (Oxford: Oxford University Press, 2003); Andrew Scull, Madness in Civilization: A Cultural History of Insanity, from the Bible to Freud, from the Madhouse to Modern Medicine (London: Thames and Hudson, 2015).

82. Crammer, St John's, 4.

83. Eric Cassell, The Healer's Art: A New Approach to the Doctor-Patient Relationship (Harmondsworth: Penguin Books, 1978), 42.

84. Cecil Helman, "Disease Versus Illness in General Practice," Journal of the Royal College of General Practitioners 31 (1981): 548-52, 548. 
85. George Savage, “The Presidential Address, Delivered at the Opening Meeting of the Section of Psychiatry of the Royal Society of Medicine, on October 22nd, 1912," Journal of Mental Science 59 (1913) 14-27, 14.

86. Medico-Psychological Association (MPA), Handbook for the Instruction of Attendants on the Insane (London: Baillière, Tindall, \& Cox, 1885).

87. Neil Brimblecombe, "Asylum Nursing as a Career in the United Kingdom, 1890-1910," Journal of Advanced Nursing 55 (2006): 770-77, 771 .

88. David Berguer, The Friern Hospital Story: The History of a Victorian Lunatic Asylum (London: Chaville Press, 2012), 106.

89. Eric Pryor, Claybury 1893-1993: A Century of Caring (London: Forest Healthcare, Mental Health Care Group, 1993), 64.

90. Colney Hatch $\mathrm{H} 12 / \mathrm{CH} / \mathrm{C} / 04 / 004$ Male attendants' wages book 1917-1918 LMA; H12/CH/C/03/004 Officers' salaries book 19101917 LMA.

91. Hanwell H11/HLL/C/05/008 Female attendants' fine book 19111916 LMA.

92. Claybury LCC/MIN/00947 Meetings, 2 March 1916, 56; 30 March 1916, 73 LMA.

93. Colney Hatch $\mathrm{H} 12 / \mathrm{CH} / \mathrm{B} / 18 / 004$ Photographs of female patients 1918-1920; H12/CH/B/19/003 Photographs of male patients 19081920 LMA.

94. Katherine Rawling, "The Annexed Photos Were Taken Today: Photographing Patients in the Nineteenth-Century Lunatic Asylum," Social History of Medicine (2019): https://doi.org/10.1093/shm/ hkz060.

95. Rawling, "The Annexed Photos": 10.

96. Ludmilla Jordanova, “Approaching Visual Materials," 30-47, in Research Methods for History, ed. Simon Gunn and Lucy Faire (Edinburgh: Edinburgh University Press, 2016): 31.

97. MPA, Handbook for Attendants on the Insane (6th Edition) (London: Baillière, Tindall and Cox, 1911), 216.

98. Tobia, "Bristol Lunatic Asylum": 7.

99. Jonathan Andrews, “Case Notes, Case Histories, and the Patient's Experience of Insanity at Gartnavel Royal Asylum, Glasgow, in the Nineteenth Century," Social History of Medicine 11 (1998): 255-81, 265.

100. Colney Hatch LCC/MIN/01005 Meeting, 24 March 1916, 103-4 LMA; Lunacy Act 1890 section 38 (4).

101. Ayers Gwendoline, England's First State Hospitals and the Metropolitan Asylums Board, 1867-1930 (London: Wellcome Institute of the History of Medicine, 1971); Frederick Mott, "Tuberculosis in London County Asylums," Archives of Neurology and Psychiatry from the Pathological 
Laboratory of the London County Asylums, Claybury, Essex 4 (1909): 70-116, 74 .

102. Stefan Goebel and Jerry White, "London and the First World War," London Journal 41 (2016): 199-218, 200.

103. Joanna Bourke, Fear: A Cultural History (London: Virago, 2005) 225.

104. BoC, "Orders for Destruction of Documents," 31 March $1909 \mathrm{MH}$ 51/723 TNA.

105. Public Record Office Act 1877 and 1898. "Rules for the Disposal of Documents which are not of Sufficient Value to Justify their Preservation in the Public Record Office," MH 51/723 TNA.

106. Claybury LCC/MIN/00945 Meeting, 1 October 1914, 185-86 LMA; Public Record Office circular, "Destruction of Papers, Records and Documents," April 1918 MH 51/723 TNA; LCC LCC/MIN/00581 Meeting, 21 March 1916, 476 LMA.

107. BoC, unsigned note, 26 July 1932; Charles Raithby, 2 January 1933, MH 51/723 TNA.

Open Access This chapter is licensed under the terms of the Creative Commons Attribution 4.0 International License (http://creativecommons.org/licenses/ by $/ 4.0 /)$, which permits use, sharing, adaptation, distribution and reproduction in any medium or format, as long as you give appropriate credit to the original author(s) and the source, provide a link to the Creative Commons license and indicate if changes were made.

The images or other third party material in this chapter are included in the chapter's Creative Commons license, unless indicated otherwise in a credit line to the material. If material is not included in the chapter's Creative Commons license and your intended use is not permitted by statutory regulation or exceeds the permitted use, you will need to obtain permission directly from the copyright holder.

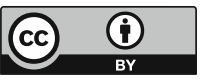

